\title{
Layer-specific serotonergic induction of long-term depression in the prefrontal cortex of rats
}

\author{
Dongchul Shin ${ }^{1}$, Kwang-Hyun Cho', Kayoung Joo' ${ }^{1}$, and Duck-Joo Rhie ${ }^{1,2, *}$ \\ ${ }^{1}$ Department of Physiology, ${ }^{2}$ Catholic Neuroscience Institute, College of Medicine, The Catholic University of Korea, Seoul 06591, Korea
}

\section{ARTICLE INFO}

Received September 24, 2020

Revised September 29, 2020

Accepted October 4, 2020

*Correspondence

Duck-Joo Rhie

E-mail: djrhie@catholic.ac.kr

Key Words

Cholinergic

Layer 2/3

Orbitofrontal cortex

Pyramidal cell

Synaptic transmission

\begin{abstract}
Layer 2/3 pyramidal neurons (L2/3 PyNs) of the cortex extend their basal dendrites near the soma and as apical dendritic tufts in layer 1 , which mainly receive feedforward and feedback inputs, respectively. It is suggested that neuromodulators such as serotonin and acetylcholine may regulate the information flow between brain structures depending on the brain state. However, little is known about the dendritic compartment-specific induction of synaptic transmission in single PyNs. Here, we studied layer-specific serotonergic and cholinergic induction of long-term synaptic plasticity in L2/3 PyNs of the agranular insular cortex, a lateral component of the orbitofrontal cortex. Using FM1-43 dye unloading, we verified that local electrical stimulation to layers 1 (L1) and 3 (L3) activated axon terminals mostly located in $\mathrm{L} 1$ and perisomatic area (L2/3). Independent and AMPA receptor-mediated excitatory postsynaptic potential was evoked by local electrical stimulation of either $\mathrm{L} 1$ or L3. Application of serotonin $(5-\mathrm{HT}, 10 \mu \mathrm{M})$ induced activity-dependent longterm depression (LTD) in L2/3 but not in L1 inputs. LTD induced by 5 -HT was blocked by the $5-\mathrm{HT}_{2}$ receptor antagonist ketanserin, an NMDA receptor antagonist and by intracellular $\mathrm{Ca}^{2+}$ chelation. The $5-\mathrm{HT}_{2}$ receptor agonist $\alpha-\mathrm{me}-5-\mathrm{HT}$ mimicked the LTD induced by 5 -HT. However, the application of carbachol induced muscarinic receptor-dependent LTD in both inputs. The differential layer-specific induction of LTD by neuromodulators might play an important role in information processing mechanism of the prefrontal cortex.
\end{abstract}

\section{INTRODUCTION}

Cerebral cortex integrates bottom-up sensory and top-down associative information in a multilayered structure consisting of excitatory pyramidal neurons (PyNs) with intermingled inhibitory interneurons. PyNs in layers $2 / 3$ (L2/3) and 5 receive the two types of information mainly in basal dendrites and distal apical dendrites, respectively [1]. Multiple basal dendrites of L2/3 PyNs surround the soma and a single apical dendrite is extended into layer 1 (L1) as dendritic tufts [2]. These two dendritic compartments exhibit different properties of synaptic transmission and integration due to differential expression of ion channels and intracellular signaling molecules [3]. Neuromodulators such as acetylcholine and serotonin exert a profound effect on a vast array of neuronal functions in the central nervous system, such as neuronal excitability, learning and memory, experience-dependent development and brain state $[4,5]$. Since neuromodulators control information flow depending on brain state [6], the layerspecific neuromodulation of synaptic transmission might be critical to brain state-dependent functions. In our previous studies, muscarinic stimulation induced long-term potentiation (LTP) or endocannabinoid-dependent long-term depression (LTD) in basal dendrites, but not in distal apical dendrites of L2/3 PyNs in the primary visual cortex $[7,8]$. Serotonin $(5-\mathrm{HT})$ facilitates GABAer-

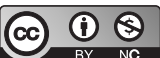

This is an Open Access article distributed under the terms of the Creative Commons Attribution Non-Commercial License, which permits unrestricted non-commercial use, distribution, and reproduction in any medium, provided the original work is properly cited. Copyright @ Korean J Physiol Pharmacol, pISSN 1226-4512, elSSN 2093-3827
Author contributions: D.S. conducted the experiments. K.H.C. and D.J.R. designed the study. D.S. and K.J. analyzed experimental data. D.S., K.H.C., and D.J.R. wrote the manuscript. 
gic currents in perisomatic area, but not in distal apical dendrites of the same PyNs [9]. However, this differential neuromodulation between two dendritic compartments is not known in other cortical areas such as prefrontal association cortex.

The prefrontal cortex (PFC) is critical for high-level executive functions and cognitive control by integrating the processed sensory and emotional signals [10-13]. Among the prefrontal brain regions, the orbitofrontal cortex (OFC) including the agranular insular (AI) cortex plays an essential role in value-based decision making [14-16]. In the OFC, the feedforward inputs from other cortex and inputs from the amygdala terminate preferentially onto L2/3 while nonspecific thalamic relay nucleus and higher order cortex projects mainly onto L1 in rats [17-19] and macaque monkeys [20]. Especially, the thalamic nucleus submedius projects primarily to layers $2 / 3 / 5$ of the OFC in mice [21]. The PFC also receives dense serotonergic innervation from dorsal and medial raphe nuclei and cholinergic innervation from the basal forebrain and basal ganglia [22,23]. The gating and polarity of synaptic plasticity in the cortex can be controlled by neuromodulators such as 5-HT and acetylcholine (ACh) [24-26]. The regulatory roles of various serotonergic and cholinergic stimulation in the induction of LTP and LTD of the medial PFC (mPFC) are relatively well established $[25,27,28]$. However, long-term synaptic plasticity in the lateral portion of the PFC such as AI cortex is not known. Moreover, the layer-specific modulation of synaptic transmission in L2/3 PyNs would be critical for the cognitive function of the PFC.

We investigated the layer-specific neuromodulation of synaptic transmission as a general phenomenon in the neocortex by analyzing the layer-specific serotonergic and cholinergic induction of long-term synaptic plasticity of glutamatergic transmission in L2/3 PyNs of the OFC. We found that serotonin induced input-specific LTD on perisomatic area, but not in distal apical dendrites. In contrast, cholinergic stimulation induced muscarinic LTD in both inputs. Our findings suggest that layer-specific neuromodulation of synaptic transmission might be generally applicable to the neocortex, and thus presents a novel cellular mechanism in cognitive processes.

\section{METHODS}

\section{Slice preparation}

Coronal slices of the frontal cortex were prepared from Sprague-Dawley (SD) rats (Orient Bio Co., Ltd., Seongnam, Korea) on days $21-27$ after birth, which were raised under standard conditions $\left(23^{\circ} \mathrm{C} \pm 1^{\circ} \mathrm{C}, 12 / 12 \mathrm{~h} /\right.$ light/dark cycle). Animal care and surgical procedures were conducted by the institutional animal care and use committee (IACUC) of the Catholic University of Korea (IACUC approval No. 2019-0024-01) and were consistent with the National Institutes of Health Guidelines for the
Care and Use of Laboratory Animals. Animals were sedated with chloral hydrate $(400 \mathrm{mg} / \mathrm{kg}$, i.p.). Brains were rapidly isolated after decapitation and immersed in ice-cold artificial cerebrospinal fluid (ACSF) containing (in mM) $125 \mathrm{NaCl}, 2.5 \mathrm{KCl}, 25 \mathrm{NaHCO}_{3}$, $1.25 \mathrm{NaH}_{2} \mathrm{PO}_{4}, 1 \mathrm{CaCl}_{2}, 2 \mathrm{MgSO}_{4}$, and $10 \mathrm{D}$-glucose bubbled with $95 \% \mathrm{O}_{2}$ and $5 \% \mathrm{CO}_{2}$. Coronal slices (300- $\mu \mathrm{m}$ thick) were prepared on a vibratome (Microm HM650V, Walldorf, Germany) and incubated in a submerged slice chamber for $30 \mathrm{~min}$ at $36.5^{\circ} \mathrm{C}$, and then left at room temperature $\left(22^{\circ} \mathrm{C}-24^{\circ} \mathrm{C}\right)$ until the recording was performed. Slices were transferred to the recording chamber and continuously perfused with the same ACSF (bubbling with $95 \% \mathrm{O}_{2}$ and $5 \% \mathrm{CO}_{2}$ ) except for the addition of $2 \mathrm{mM} \mathrm{CaCl}_{2}$ and 1 $\mathrm{mM} \mathrm{MgSO}_{4}(1-1.5 \mathrm{ml} / \mathrm{min})$.

\section{Whole-cell patch-clamp recording}

The whole-cell patch-clamp recording was performed as described previously [7]. Recording electrodes (4-6 M $\Omega$ ) were pulled from borosilicate glass pipettes (World Precision Instruments, Inc., Sarasota, FL, USA) using a micropipette puller (MODEL P-97; Sutter Instrument Co., Novato, CA, USA). Excitatory postsynaptic potential (EPSP) was recorded with an electrode filled with a solution containing (in mM) 130 K-gluconate, $10 \mathrm{KCl}, 4 \mathrm{Mg}$-ATP, $10 \mathrm{Na}_{2}$-phosphocreatine, $0.3 \mathrm{Na}_{3}$-GTP, and 10 HEPES (pH 7.25 with KOH). The shape of L2/3 PyNs ( $\sim 300-350$ $\mu \mathrm{m}$ from pia) in the AI area of the PFC (Paxinos and Watson [29]) was visually identified with an infrared-differential interference contrast (IR-DIC) video microscope coupled to an upright microscope (BX50-WI fitted with 40x/0.80 NA immersion objective; Olympus, Tokyo, Japan) and their regular spiking patterns were confirmed. Whole-cell recording signals were acquired using an amplifier (IX2-700; Dagan, Minneapolis, MN, USA) and digitized at $20 \mathrm{kHz}$ (Digidata 1322A; Axon Instruments, Foster City, CA, USA). Using pCLAMP 10.3 software (Axon Instruments), the signals were saved to a computer hard drive (Pentium PC). The data were low-pass filtered at $5 \mathrm{kHz}$. Membrane potentials were not corrected for $\sim 14 \mathrm{mV}$ calculated junction potential. The typical access resistance was $12-15 \mathrm{M} \Omega$, and the bridge balance set was optimized in the experiment. The input resistance was measured by injecting negative current $(-50 \mathrm{pA}, 150 \mathrm{~ms})$ into the soma (every $60 \mathrm{sec})$. Bipolar tungsten electrode $(100 \mu \mathrm{m}$ in diameter, SNE-100; Kopf Instruments, Tujunga, CA, USA) and glass electrode (20$\mu \mathrm{m}$ tip diameter, filled with ACSF) were located at layer 3 (L3, $\sim 50 \mu \mathrm{m}$ downward and $\sim 100 \mu \mathrm{m}$ laterally from the soma) and corresponding L1 ( $\sim 5 \mu \mathrm{m}$ from pia), respectively, for the local electrical stimulations. EPSPs were evoked by paired-pulse stimulation (40-ms interval) with a brief square current pulse (0.2-ms duration) using a constant-current isolation unit (A360; World Precision Instruments). The EPSP amplitude changes were monitored at $0.05 \mathrm{~Hz}$. The stimulus intensity was adjusted to obtain stable baseline EPSPs (5-8 mV). The average amplitude of EPSP was measured at 30-40 min after wash-out of serotonin or car- 
bachol (CCh) and compared with that of baseline EPSPs. In some experimental sets, 6,7-dinitroquinoxaline-2,3-dione disodium salt (DNQX, $20 \mu \mathrm{M}$ ) and d-(-)-2-amino-5-phosphonopentanoic acid (D-AP5, $50 \mu \mathrm{M}$ ) were added to ACSF to confirm glutamatergic synaptic transmission. The paired-pulse ratio (PPR) was determined as the amplitude of the second EPSP compared with that of the first EPSP evoked paired-pulse stimulation (40-ms interval). The amplitude of the second EPSP was determined from the single exponential fit of the first EPSP.

\section{FM1-43 unloading}

The unloading protocol of fluorescence dye, FM1-43 was similar to that described previously [8]. The changes in fluorescence intensity of FM1-43 indicate synaptic vesicle recycling at presynaptic terminals. Synaptic stimulation releases the FM1-43 from presynaptic vesicles resulting in decreased fluorescence intensity of FM1-43 [30]. To load FM1-43 (Molecular Probes, Eugene, OR, USA) into synaptic vesicles, slices were exposed to high-potassium (40 mM) ACSF for 2 min with $8 \mu \mathrm{M}$ FM1-43. To reduce nonspecific binding of the FM1-43 to tissue, slices were washed with 1 mM ADVASEP-7 for 2 min in ACSF and further perfused with 0.1 mM ADVASEP-7 in ACSF for 50 min. To unload FM1-43, elec- tric stimulation $(2 \mathrm{~Hz})$ was delivered to either $\mathrm{L} 1$ or $\mathrm{L} 3$ for $2 \mathrm{~min}$ with glass pipettes or tungsten bipolar electrodes with 2- to 3-fold stimulus intensity for baseline EPSP amplitude. All loading and unloading procedures of FM1-43 were conducted using ACSF containing ionotropic glutamatergic blockers D-AP5 $(50 \mu \mathrm{M})$ and DNQX $(20 \mu \mathrm{M})$ to prevent excitotoxic damage. High-potassium ACSF was applied for $5 \mathrm{~min}$ at the end of experiments for the background subtraction and normalization of fluorescence signal. Fluorescence signals were acquired on the microscope for wholecell patch-clamp recording equipped with a monochromator (Polychrome V; TILL Photonics GmbH, Gräfelfing, Germany), a long-pass filter $(510 \mathrm{~nm})$, and a CCD camera (Retiga-2000RV; QImaging, Surrey, BC, Canada). Wavelengths for excitation and emission of FM1-43 dye were $480 \mathrm{~nm}$ and $532 \mathrm{~nm}$, respectively. Fluorescence images were collected at 5-sec intervals with 10-70 ms light exposure and captured using TILLvisION software (TILL Photonics).

\section{Drugs}

Drugs including 5-Hydroxytryptamine (5-HT), DNQX, 8-hydroxy-2-dipropylaminotetralin hydrobromide (8-OH-DPAT), $N$-(piperidin-1-yl)-5-(4-iodophenyl)-1-(2,4-dichlorophenyl)-4-
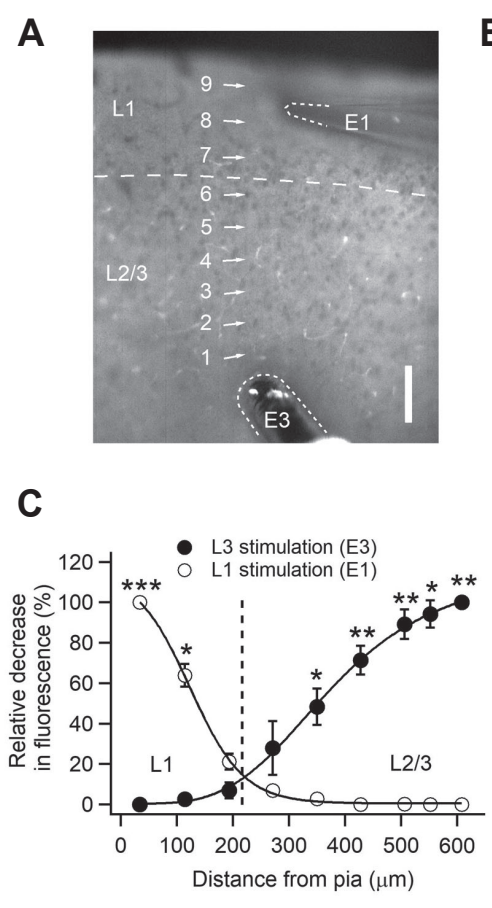

D
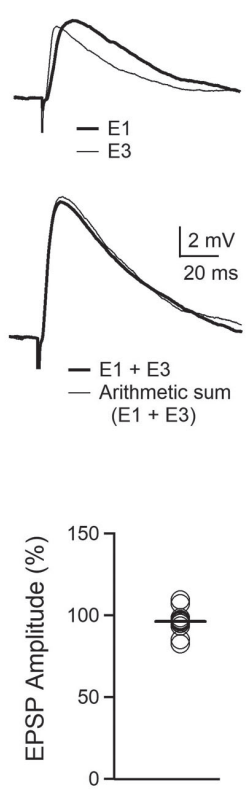

Fig. 1. Layer-specific activation of Layer $2 / 3$ pyramidal neurons with local electrical stimulation. Experimental configuration (10x objective image) showing numbered regions of interest (ROIs) with stimulating electrodes marked with E1 for layer 1 (L1) stimulation and E3 for layer 3 (L3) stimulation. Scale $=100 \mu \mathrm{m}$. (B) Fluorescence changes in ROls with time (5-sec interval). E1 and E3 were applied at $2 \mathrm{~Hz}$ (bars). Data are from a representative experiment $(n=3)$. (C) Spatial profiles of relative fluorescence changes against distance from the pia. The relative decrease in fluorescence to the maximal decrease was plotted. ${ }^{*} p<0.05,{ }^{* *} p<0.01,{ }^{* * *} p<0.001$ compared with L1 or L3 stimulation. (D) Activation of non-overlapping synapses. Upper traces show representative EPSPs evoked by E1 and E3. Middle traces show representative EPSP evoked by combining E1 with E3 and arithmetic sum of corresponding E1-EPSP and E3-EPSP. Lower panel shows individual data of the amplitude of arithmetic sum relative to the amplitude of EPSPs evoked by combined E1 and E3 $(n=12)$. EPSP, excitatory postsynaptic potential. 
methyl-1H-pyrazole-3-carboxamide (AM251), D-AP5, 1-(mchlorophenyl) biguanide hydrochloride (mCPBG), NAN-190, ketanserin, and 1,2-bis(2-aminophenoxy)ethane- $N, N, N^{\prime}, N^{\prime}$ tetraacetic acid (BAPTA) were purchased from Tocris Bioscience (Bristol, UK). ondansetron hydrochloride, $\alpha$-methyl-5hydroxytryptamine ( $\alpha$-me-5-HT), CCh, and atropine were purchased from Sigma-Aldrich (St Louis, MO, USA). BAPTA was included in the pipette solution. NAN-190 and AM251 were dissolved in dimethyl sulfoxide (DMSO, 0.1\%).

\section{Statistical analysis}

Data are expressed as mean \pm standard error. Statistical comparisons were performed using paired or unpaired two-tailed Student's t-test and two-way ANOVA with Tukey's multiple comparisons. The level of significance was set at $\mathrm{p}<0.05$.

\section{RESULTS}

\section{Layer-specific activation of layer 2/3 pyramidal neurons with local electrical stimulation}

Whole-cell patch-clamp recording was performed in L2/3 PyNs (300-400 $\mu \mathrm{m}$ from the pia) of the AI cortex, a part of OFC [14,16], in 3-week-old rats with local electrical stimulation of corresponding L1 and L3. In the primary visual cortex, as reported previously, these local stimulations activated non-overlapping synapses located in distal apical dendrites and basal dendrites, respectively, using unloading experiment of FM1-43 dye [8]. In the present study, we analyzed the spatial profile of unloaded FM1-43 dye by stimulation of L1 or L3 in the OFC (Fig. 1A-C). Stimulation of L1 resulted in an apparent decrease in fluorescence almost limited to L1 $\left(F_{8,36}=103.5, \mathrm{p}<0.001\right)$, and the stimulation was reduced far less in deeper L2/3 near the soma of PyNs. However, the repeated stimulation of L3 reduced fluorescence near the soma (300-600 $\mu \mathrm{m}$ from the pia). These results demonstrated that local electrical stimulation of L1 and L3 mainly activated synapses in distal apical dendrites and perisomatic dendrites, respectively. This distance profile of stimulation was similar to that of the primary visual cortex [8]. Based on these results, the two stimuli were used to evoke layer-specific activation of synaptic transmission in L2/3 PyNs of the OFC.

Next, we investigated whether local electrical stimulation of L1 and L3 activated non-overlapping array of synapses (Fig. 1D). The amplitude of EPSPs evoked by simultaneous stimulation of L1 and L3 $(9.5 \pm 0.3 \mathrm{mV}, \mathrm{n}=12)$ was similar to that of the arithmetic sum of each L1-EPSP and L3-EPSP $(9.9 \pm 0.4 \mathrm{mV}, \mathrm{p}=0.107)$. The peak time $(12.1 \pm 1.2 \mathrm{~ms})$ and decay time constant $(58.8 \pm 10.9$ $\mathrm{ms})$ of L1-EPSPs were longer than those of L3-EPSPs (6.4 \pm 0.4 $\mathrm{ms}, \mathrm{p}<0.001$ and $41.3 \pm 5.2 \mathrm{~ms}, \mathrm{p}<0.05)$. Consistent with layerspecific activation of axon terminals demonstrated in the imag- ing experiment, these results indicate that the stimulation of L1 and L3 specifically activated synapses in distal apical dendrites and perisomatic dendrites including basal dendrites, respectively, in L2/3 PyNs of the OFC.

To investigate whether EPSP was mediated by AMPA- and NMDA-type glutamate receptors, we recorded EPSPs in the presence of the AMPA receptor blocker DNQX and the NMDA receptor blocker D-AP5 (Fig. 2). We evoked EPSPs with 5-8 mV amplitude in the present study. Application of D-AP5 $(50 \mu \mathrm{M})$ did not change the amplitude of EPSPs (L1 stimulation: 100.6\% $\pm 3.9 \%, n$ $=6, \mathrm{p}=0.877$; L3 stimulation: $98.8 \% \pm 1.3 \%, \mathrm{n}=5, \mathrm{p}=0.437)$. Coapplication of DNQX $(20 \mu \mathrm{M})$ with D-AP5 abolished synaptic response (L1 stimulation: $2.6 \% \pm 0.6 \%, \mathrm{p}<0.001$; L3 stimulation: $3.8 \% \pm 0.4 \%, \mathrm{p}<0.001)$. These results indicate that EPSPs evoked by local electrical stimulation resulted mostly from the activation of AMPA receptors in L2/3 PyNs of the OFC.

\section{Layer-specific serotonergic modulation of glutamatergic transmission in L2/3 PyNs}

AMPA receptor-mediated EPSPs were recorded by applying paired-pulse electrical stimulation (40-ms interval) of L1 and L3 alternating in a single PyN. During bath application of 5-HT $(10 \mu \mathrm{M}, 10 \mathrm{~min})$ the amplitude of L1-EPSPs decreased by $30 \%$ and then recovered to the baseline level $30-40 \mathrm{~min}$ after washout

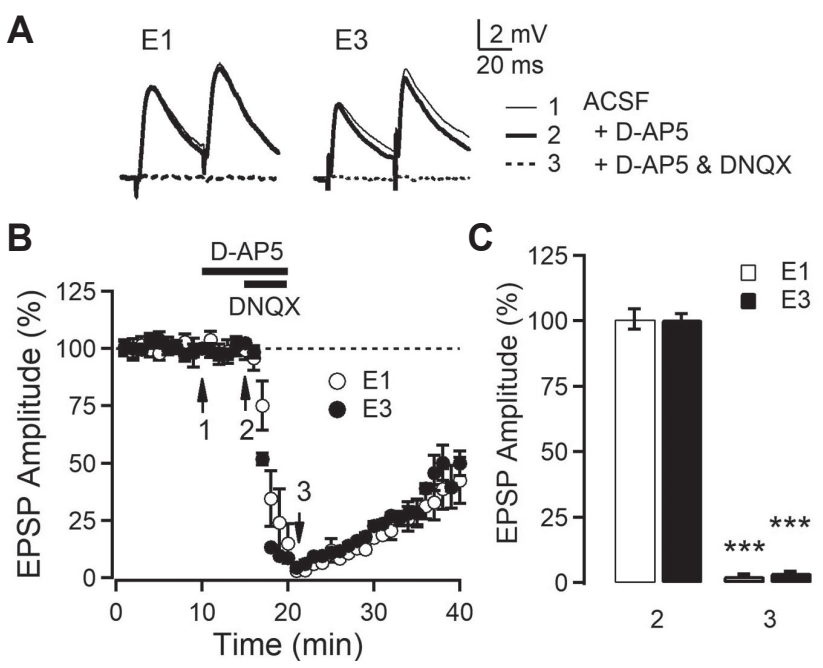

Fig. 2. AMPA receptor-mediated synaptic transmission in Layer $2 / 3$ (L2/3) pyramidal neurons of orbitofrontal cortex. (A) Representative EPSPs evoked by L1 and L3 stimulation (E1 and E3, respectively). The average EPSP waveforms recorded during $1 \mathrm{~min}$ at the time indicated by numbered arrows in B. (B) Time course of EPSP amplitude with the application of blockers. The amplitude of first EPSPs evoked by pairedpulse stimulation in the presence and absence of D-AP5 $(50 \mu \mathrm{M})$ and/ or DNQX $(20 \mu \mathrm{M})$ in bath solution. (C) Summary plot of EPSP amplitude by E1 $(n=6)$ and E3 $(n=5) .{ }^{* * *} p<0.001$ compared with baseline. EPSP, excitatory postsynaptic potential; D-AP5, d-(-)-2-amino-5-phosphonopentanoic acid; DNQX, 6,7-dinitroquinoxaline-2,3-dione disodium salt; ACSF, artificial cerebrospinal fluid. 

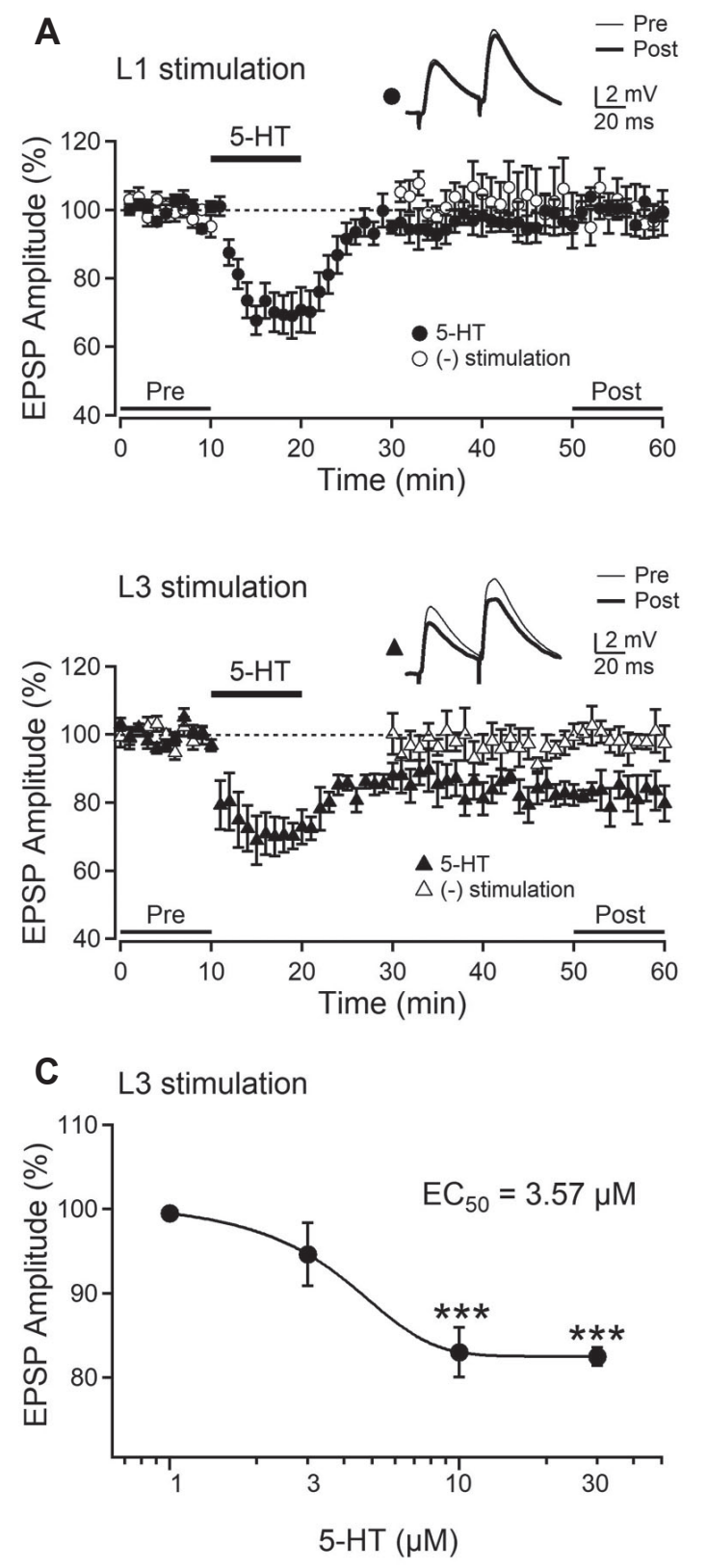

B

L1 stimulation
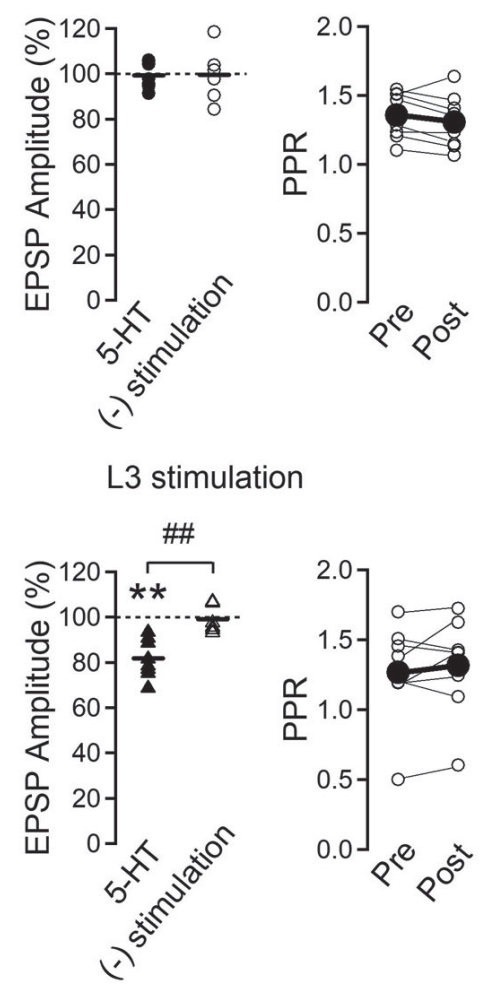

Fig. 3. Serotonergic induction of longterm depression (LTD) in the Layer $2 / 3(L 2 / 3)$ pyramidal neurons of orbitofrontal cortex. (A) Time course of average EPSP amplitude evoked by $\mathrm{L} 1$ and L3 stimulation. Serotonin (5-HT; 10 $\mu \mathrm{M}, 10 \mathrm{~min}$ ) was applied in bath solution (closed symbols: $n=9$ ). In some experiments electrical stimulation was omitted during the application of 5-HT and until 10 min after washout (open symbols: $\mathrm{n}$ =6). Insets show average EPSPs taken at the time indicated from a representative experiment. (B) Left panels show individual data and averages (thick solid lines). Right panels show the change in pairedpulse ratio (PPR) of closed symbols of the left panels. ${ }^{* *} \mathrm{p}<0.01$ compared with the baseline and ${ }^{\# \#} p<0.01$. (C) Concentration response plot of EPSP amplitude with $\mathrm{L} 3$ stimulation. The curve was fitted by sigmoid function $\left(E C_{50}=3.57 \mu \mathrm{M}\right)$. *** $p<0.001$ compared with the normal ACSF. EPSP, excitatory postsynaptic potential; ACSF, artificial cerebrospinal fluid.
$(98.6 \% \pm 1.8 \%, \mathrm{n}=9, \mathrm{p}=0.632)$ (Fig. 3A, B). Conversely, the amplitude of L3-EPSP decreased from the baseline to $83.0 \% \pm 2.9 \%$ (n $=9, \mathrm{p}<0.001$ ). Therefore, serotonergic stimulation induced inputspecific LTD activated by L3 stimulation, but not by stimulation. PPR was not changed in L1-EPSP $(1.37 \pm 0.06$ to $1.33 \pm 0.06, n=9$, $\mathrm{p}=0.163)$ and L3-EPSP $(1.29 \pm 0.11$ to $1.32 \pm 0.10, \mathrm{n}=9, \mathrm{p}=0.561)$ (Fig. 3B). In a previous study, combining 5-HT application with tetanic stimulation induced $\sim 25 \%$ LTD in the PFC [25]. In the present study, we also applied tetanic stimulation at the end of 5 -HT treatment, which induced a rather smaller magnitude of LTD $(91.8 \% \pm 1.6 \%$ from the baseline, $n=6, p<0.01)$. To further investigate the activity dependence of LTD, the test stimulation was turned off during the application of 5-HT and for $10 \mathrm{~min}$ after washout (Fig. 3A, B) [7,31]. Without synaptic activity during
5-HT application, no LTD was induced in L3-EPSP $(99.1 \% \pm 2.4 \%$, $\mathrm{n}=6, \mathrm{p}=0.736)$ or L1-EPSP $(99.5 \% \pm 4.86 \%, \mathrm{n}=6, \mathrm{p}=0.931)$. These results indicate that 5-HT induced LTD in a layer-specific and an activity-dependent manner. The concentration-dependent response of 5-HT to L3-EPSP yielded $\mathrm{EC}_{50}$ values of $3.57 \mu \mathrm{M}$ ( $\mathrm{n}=$ 5-9) (Fig. 3C). Thus, $10 \mu \mathrm{M}$ concentration of 5-HT was used to investigate the cellular mechanism of L3 LTD in subsequent experiments.

\section{5- $\mathrm{HT}_{2}$ receptor mediates serotonergic LTD induction}

The 5- $\mathrm{HT}_{1 \mathrm{~A}}$ and 5- $\mathrm{HT}_{2 \mathrm{~A}}$ receptors are the most prevalent 5- $\mathrm{HT}$ receptor subtypes in PyNs of the PFC [10]. In the following experiment, we investigated the 5-HT receptor subtypes involved 
in layer-specific serotonergic induction of LTD using specific antagonists and agonists for $5-\mathrm{HT}_{1 \mathrm{~A}}, 5-\mathrm{HT}_{2}$ and $5-\mathrm{HT}_{3}$ receptors (Fig. 4). The $5-\mathrm{HT}_{1 \mathrm{~A}}$ receptor agonist $8-\mathrm{OH}-\mathrm{DPAT}(10 \mu \mathrm{M})$ and the $5-\mathrm{HT}_{3}$ receptor agonist $\mathrm{mCPBG}(10 \mu \mathrm{M})$ failed to induce LTD in L3-EPSP $(100.1 \% \pm 2.5 \%, \mathrm{n}=6, \mathrm{p}=0.969 ; 99.0 \% \pm 2.3 \%, \mathrm{n}=$ $6, \mathrm{p}=0.730$; respectively). In contrast, the $5-\mathrm{HT}_{2}$ receptor agonist $\alpha$-me-5-HT $(10 \mu \mathrm{M})$ mimicked the LTD induction by 5 -HT $(82.1 \% \pm 3.4 \%, \mathrm{n}=6, \mathrm{p}<0.01)$. Both NAN-190 $(10 \mu \mathrm{M})$, a $5-\mathrm{HT}_{1 \mathrm{~A}}$ receptor antagonist $(87.9 \% \pm 3.6 \%, \mathrm{n}=5, \mathrm{p}<0.05)$ and ondansetron $(10 \mu \mathrm{M})$, a $5-\mathrm{HT}_{3}$ receptor antagonist $(84.9 \% \pm 4.6 \%, \mathrm{n}=$ $6, \mathrm{p}<0.05)$, failed to inhibit LTD induced by 5 -HT application, respectively. However, 5-HT induction of L3-LTD is blocked by ketanserin $(10 \mu \mathrm{M})$, a $5-\mathrm{HT}_{2}$ receptor antagonist $(98.1 \% \pm 2.5 \%, \mathrm{n}$ $=7, \mathrm{p}=0.474)$. Moreover, ketanserin abolished the effect of $\alpha$-me5 -HT $(98.1 \% \pm 2.3 \%, \mathrm{n}=6, \mathrm{p}=0.444)$. Neither 5-HT receptor agonists nor antagonists changed the amplitude of L1-EPSP (Fig. $4 \mathrm{~A})$. These results suggest that $5-\mathrm{HT}_{2}$ receptors mediate the serotonergic induction of L3-LTD in L2/3 PyNs of the OFC.

\section{LTD induction is dependent on intracellular $\mathrm{Ca}^{2+}$ via NMDA receptors}

We next investigated the involvement of intracellular $\mathrm{Ca}^{2+}$ and NMDA receptors in LTD induction. Intracellular application of BAPTA $(10 \mathrm{mM})$, a $\mathrm{Ca}^{2+}$ chelating agent, inhibited L3LTD induced by 5 -HT $(99.2 \% \pm 1.8 \%, \mathrm{n}=6, \mathrm{p}=0.681)$ while L1EPSP was not changed $(100.6 \% \pm 3.0 \%, \mathrm{n}=6, \mathrm{p}=0.830)$ (Fig. $5 \mathrm{~A}$ ). NMDA receptor antagonist D-AP5 $(50 \mu \mathrm{M})$ inhibited L3-LTD $(98.6 \% \pm 2.1 \%, \mathrm{n}=6, \mathrm{p}=0.547)$, but not L1-EPSP $(98.2 \% \pm 1.0 \%$, $\mathrm{n}=5, \mathrm{p}=0.157)$ (Fig. 5B). These results suggest that the increase in intracellular $\mathrm{Ca}^{2+}$ via NMDA receptors might mediate 5-HT induction of L3-LTD. We also determined whether endocannabinoids (eCBs) were involved in the serotonergic induction of LTD in the $\mathrm{OFC}$, since eCBs generated by the increase in intracellular $\mathrm{Ca}^{2+}$ mediated muscarinic LTD in perisomatic synapses of the visual cortex [8]. Application of the cannabinoid (CB) receptor antagonist AM251 $(5 \mu \mathrm{M})$ failed to inhibit L3-LTD $(83.7 \% \pm 4.5 \%$, $\mathrm{n}=6, \mathrm{p}<0.05$ ), while the amplitude of L1-EPSP was not changed $(97.5 \% \pm 3.4 \%, n=5, p=0.517)$ (Fig. $5 \mathrm{C}$ ). These data suggest that eCB signaling played no role in serotonergic LTD in L2/3 PyNs of the OFC.

\section{Cholinergic induction of LTD}

CCh $(10 \mu \mathrm{M}, 10 \mathrm{~min})$ was bath-applied to induce cholinergic LTD and compared with our previous results in the primary visual cortex $[7,8]$. CCh decreased the amplitude of the baseline amplitude of L1-EPSP to $81.1 \% \pm 3.4 \%(\mathrm{n}=5, \mathrm{p}<0.01)$ and L3-EPSP to $86.8 \% \pm 2.5 \%$ ( $n=6, p<0.01)$, respectively (Fig. 6). PPR in L1LTD $(1.11 \pm 0.01$ to $1.23 \pm 0.06, \mathrm{n}=5, \mathrm{p}=0.091)$ and in L3-LTD $(1.04 \pm 0.09$ to $1.13 \pm 0.10, \mathrm{n}=6, \mathrm{p}=0.210)$ remained unchanged, indicating postsynaptic form (Fig. 6B). The muscarinic ACh re- ceptor (mAChR) blocker atropine $(10 \mu \mathrm{M})$ in the bath solution blocked the induction of L1-LTD $(97.4 \% \pm 2.8 \%$ of the baseline, $\mathrm{n}=7, \mathrm{p}=0.389)$ and L3-LTD $(98.7 \% \pm 1.4 \%$ of the baseline, $\mathrm{n}=5$, $\mathrm{p}=0.454)$. Therefore, the activation of ACh receptors induced muscarinic LTD in both synaptic inputs on distal apical and peri-
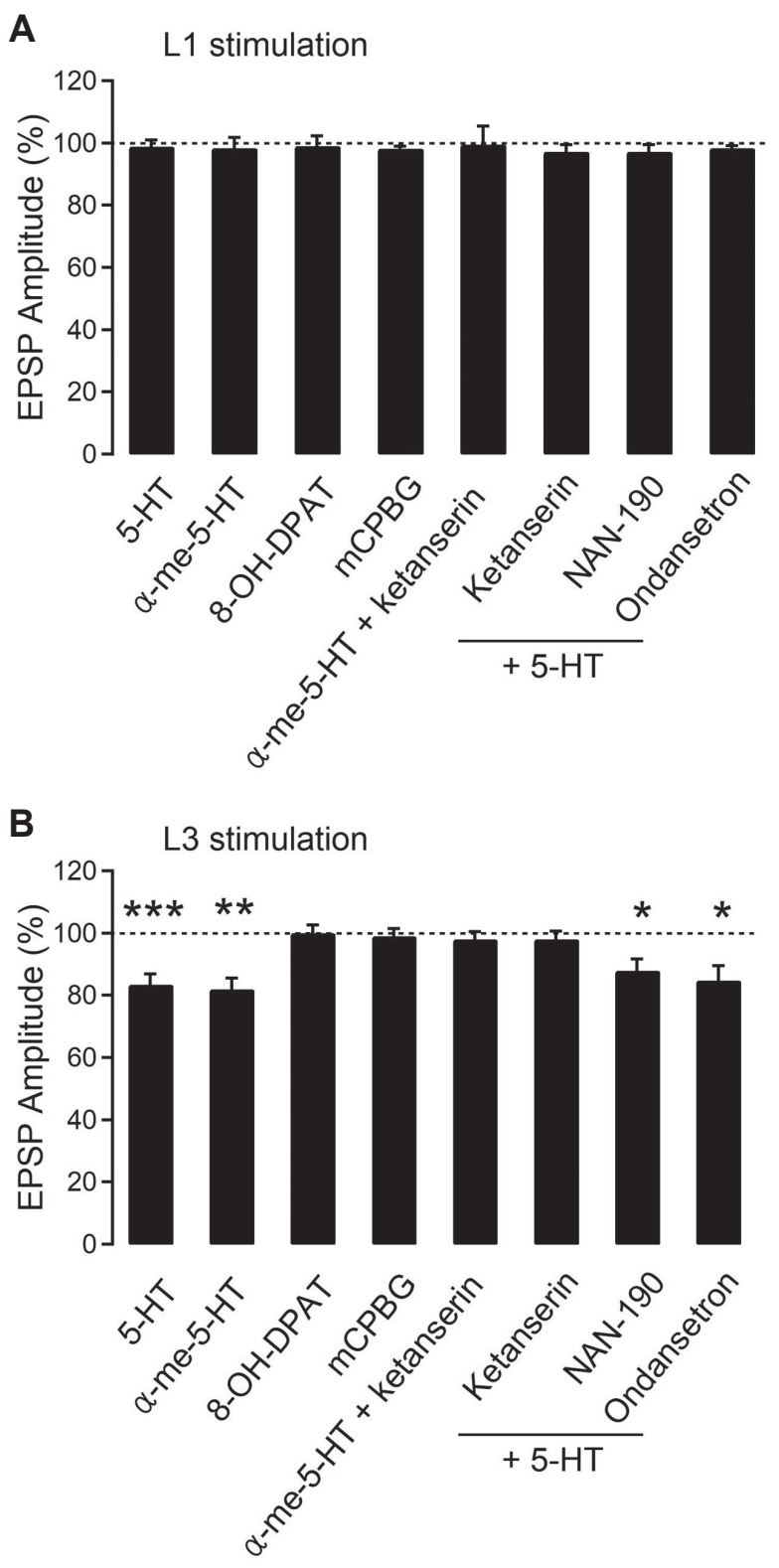

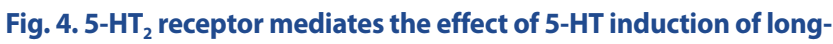
term depression (LTD). Summary plots of average EPSP amplitude with $L 1$ (A) and L3 (B) stimulation of Layer 2/3 (L2/3) pyramidal neurons of orbitofrontal cortex. 5 -HT antagonists were applied into the bath throughout the experiments. 5-HT $(n=9), \alpha-m e-5-\mathrm{HT}(n=6), 8-\mathrm{OH}-$ DPAT $(n=6), \operatorname{mCPBG}(n=7), \alpha-m e-5-H T+$ ketanserin $(n=6)$, ketanserin $(n=7), N A N-190(n=5)$, and ondansetron $(n=6) .5-H T$, serotonin; 8-OH-DPAT, 8-hydroxy-2-dipropylaminotetralin hydrobromide; mCPBG, 1 -(m-chlorophenyl) biguanide hydrochloride; $\alpha-$ me-5-HT, $\alpha$-methyl-5hydroxytryptamine; EPSP, excitatory postsynaptic potential. ${ }^{*} p<0.05$, ${ }^{* *} p<0.01,{ }^{* * *} p<0.001$ compared with the baseline. 

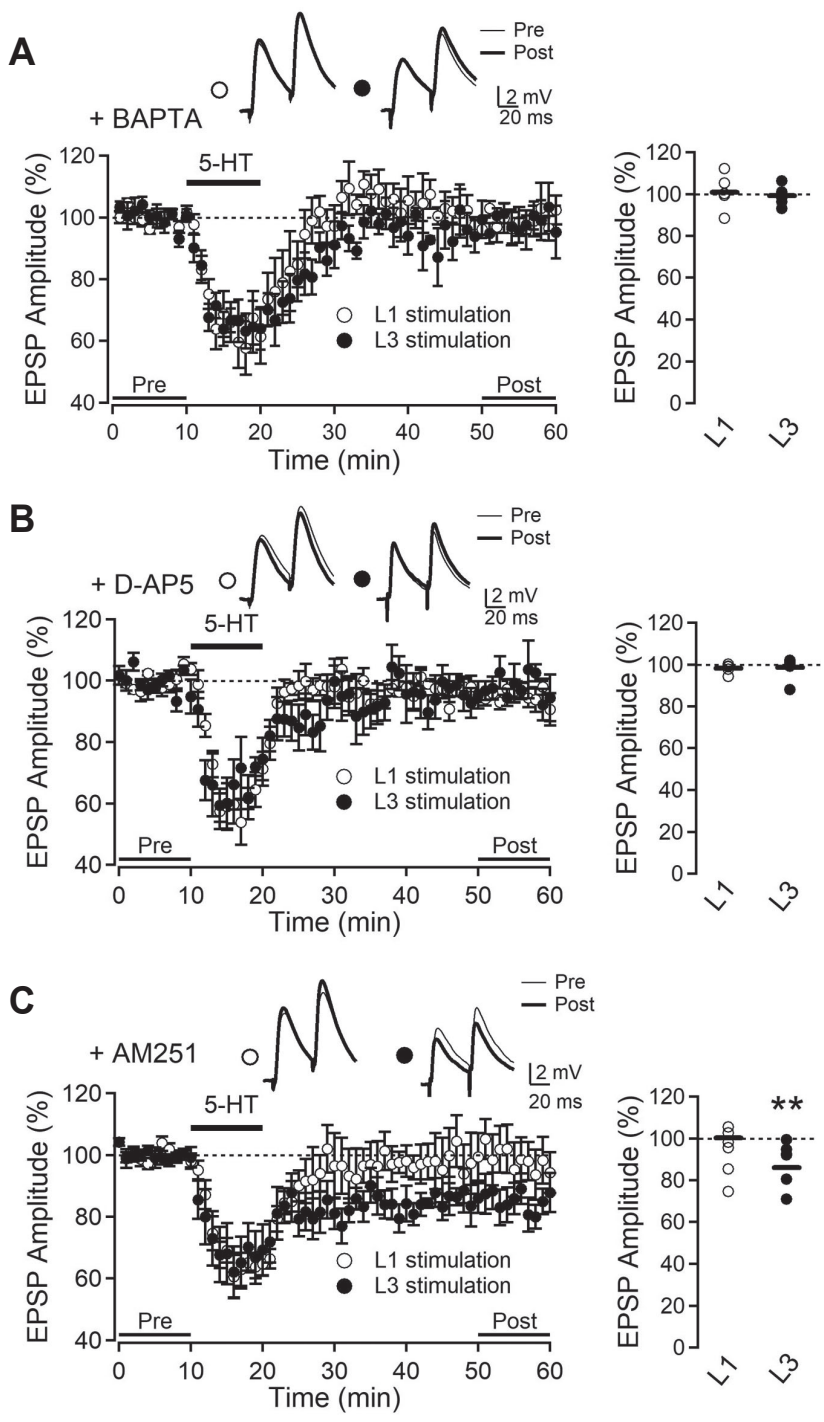

Fig. 5. Serotonergic long-term depression (LTD) is dependent on intracellular $\mathrm{Ca}^{2+}$ and NMDA receptors. (A) Time course of average EPSP amplitude in the presence of intracellular BAPTA $(10 \mathrm{mM})$ with L1 stimulation (open circle, $n=6$ ) and L3 stimulation (closed circle, $n$ =6). (B) Time course of average EPSP amplitude with bath application of D-AP5 $(50 \mu \mathrm{M})$ evoked by L1 stimulation (open circle, $n=5)$ and L3 stimulation (closed circle, $n=6$ ). (C) Time course of average EPSP amplitude with bath application of AM251 ( $5 \mu \mathrm{M})$ evoked by L1 stimulation (open circle, $n=5$ ) and L3 stimulation (closed circle, $n=6$ ). Insets show average EPSPs taken at the time indicated from a representative experiment. Right panels show EPSP amplitude in individual experiments and the average (solid line). EPSP, excitatory postsynaptic potential; BAPTA, 1,2-bis(2-aminophenoxy)ethane- $N, N, N, N^{\prime} N^{\prime}$-tetraacetic acid; D-AP5, d(-)-2-amino-5-phosphonopentanoic acid; AM251, N-(piperidin-1-yl)5-(4-iodophenyl)-1-(2,4-dichlorophenyl)-4-methyl-1H-pyrazole-3carboxamide. ${ }^{* *} \mathrm{p}<0.01$ compared with baseline (pre).

somatic dendrites in L2/3 PyN of the OFC, similar to the visual cortex. However, contrary to layer-specific serotonergic induction of LTD, cholinergic stimulation induced LTD in both inputs in the OFC.

\section{DISCUSSION}

We investigated layer-specific serotonergic and cholinergic modulation of synaptic transmission in L2/3 PyNs of the OFC. FM1-43 dye unloading demonstrated that the local electrical stimulation of L1 and L3 mainly activated inputs located in L1 and L2/3, respectively. Postsynaptic L3-LTD was induced by 5-HT but not in $\mathrm{L} 1$ inputs. 5- $\mathrm{HT}_{2}$ receptors, NMDA receptors, and increase in intracellular $\mathrm{Ca}^{2+}$ mediated L3-LTD. However, the cholinergic stimulation induced muscarinic LTD in both inputs activated by L1 and L3 stimulation. These results suggest that layer-specific neuromodulation of synaptic transmission might be an important mechanism in integration of information in L2/3 PyNs of the PFC.

\section{Layer-specific activation of synaptic transmission in L2/3 PyNs of the PFC}

In L2/3 PyNs of the PFC, distal apical dendrites in L1 receive nonspecific thalamocortical inputs whereas the perisomatic dendritic area including basal dendrites in $\mathrm{L} 2 / 3$ receive various synaptic inputs from other cortex, striatum, amygdala, and hippocampus [17-21]. Thus, L2/3 PyNs are well suited for the integration of these diverse synaptic inputs. In the present study, we used local electrical stimulation at L1 and L3 to activate synapses located in distal apical and perisomatic dendrites, respectively. Although we demonstrated that local electrical stimulation activated nearby dendritic synapse in the primary visual cortex in our previous study [8], it was not clear whether this experimental configuration could be applied in the PFC. In the present study, we demonstrated that local electrical stimulation of L1 and L3 activated synapses located in distal apical and perisomatic dendritic areas, respectively, using FM1-43 dye unloading from axon terminals (Fig. 1A-C). Consistently, rapid dynamics of L3-EPSP than L1-EPSP coincided with the distance of synaptic location of respective dendrites from the soma. Furthermore, we showed that L1-EPSP and L3-EPSP were independently evoked by the corresponding stimulation (Fig. 1D). Thus, we established that local electrical stimulation of L1 and L3 independently activated synapses located in distal apical and perisomatic dendrites, respectively, in L2/3 PyNs of the PFC. Inputs to L2/3 PyNs from other brain areas are segregated and terminated onto different dendritic compartments $[1,32]$. Various active membrane properties are specific to dendritic locations and compartments [33]. Thus, the local electrical stimulation could be an efficient experimental technique to investigate the integration properties of the PFC as well as the primary visual cortex.

\section{Serotonergic LTD and involvement of $5-\mathrm{HT}_{2}$ receptors in L2/3 PyNs}

In the PFC, 5-HT is involved in various forms of long-term 
synaptic plasticity. LTP in hippocampo-mPFC was augmented in 5-HT-depleted rats [28]. Combining 5-HT treatment with tetanic stimulation induced LTD in layers 5/6 PyNs of the PFC [25]. A 20-min exposure of 5-HT has been reported to induce LTD via activation of 5- $\mathrm{HT}_{2 \mathrm{~A}}$ receptors in $\mathrm{L} 5 \mathrm{PyNs}$ of the mPFC [34]. In our previous study, 5-HT inhibited LTP induced by theta-burst stimulation and LTD induced by low-frequency stimulation during the critical period in L2/3 PyNs of the primary visual cortex $[35,36]$. However, 5 -HT reinstated the induction of NMDA receptor-dependent LTP in 8- to 10-week-old rats [37]. In the cat visual cortex, 5-HT promotes the probability of LTP in $5-\mathrm{HT}_{2 \mathrm{C}}$ receptorrich zones and facilitates LTD induction in $5-\mathrm{HT}_{2 \mathrm{C}}$ receptor-poor zones [38]. Thus, 5-HT induces LTP and LTD in a complex manner, depending on the different 5-HT receptor subtypes, brain regions and developmental stages $[24,39,40]$. In the present study, we demonstrated that a 10-min application of 5-HT (10-30 $\mu \mathrm{M})$ induced LTD with a $17 \%$ decrease in amplitude in the OFC. In a previous study, 5-HT $(40 \mu \mathrm{M})$ alone reduced excitatory postsynaptic current (EPSC) amplitude in L5 PyNs of the PFC less than $10 \%$, whereas 5 -HT treatment combed with tetanic stimulation decreased EPSC amplitude by 25\% [25]. In the present study, we also applied tetanic stimulation combined with 5-HT $(10 \mu \mathrm{M})$, although a smaller amplitude LTD (91.8\%) was obtained. Since 5-HT expression varies in receptor subtypes and density depending on cortical areas and layers [40-42], the difference might be attributed to the different areas (mPFC vs. OFC) and layers (L2/3 vs. L5 PyNs).
Among the 14 different 5-HT receptor subtypes, 5- $\mathrm{HT}_{1 \mathrm{~A}}$, $5-\mathrm{HT}_{2 \mathrm{~A}}$ and $5-\mathrm{HT}_{3}$ are the most abundantly expressed receptors in the PFC. $5-\mathrm{HT}_{2}$ receptors are coupled to phospholipase C (PLC) and increase intracellular $\mathrm{Ca}^{2+}$. The $5-\mathrm{HT}_{2 \mathrm{~A} / \mathrm{C}}$ receptors are highly expressed at the proximal dendrites including the soma according to mRNA expression and immunohistochemical localization $[40,42]$. In previous studies, $5-\mathrm{HT}_{2}$ receptor-induced LTD in L5 PyNs of the mPFC was dependent on metabotropic glutamate receptors, in synapses activated by stimulation of either L5 [25] or L1 [34]. Spike timing-dependent LTD (t-LTD) in L1 synapses of L5 PyNs of the mPFC was induced by the activation of presynaptic NMDA receptors upon the activation of presynaptic $5-\mathrm{HT}_{2 \mathrm{~A}}$ receptors [43]. In the present study, 5-HT-induced LTD was mediated by $5-\mathrm{HT}_{2}$ receptor activation in $\mathrm{L} 2 / 3$ PyNs of the OFC. The 5-HT-induced LTD was NMDA receptor-dependent. We demonstrated that NMDA receptors did not contribute to the peak EPSP amplitude of 5-8 $\mathrm{mV}$ upon stimulation of L1 and L3. However, L3-EPSPs showed faster decay kinetics in the presence of D-AP5 in some PyNs (Fig. 2). Since the activation kinetics of NMDA receptors is slower than that of AMPA receptors [44], the small number of NMDA receptors might be activated in perisomatic dendrites by L3 stimulation. Furthermore, the local EPSP amplitude of distal synapses might be large enough to activate NMDA receptors especially in spine heads $[45,46]$. Moreover, silencing synaptic activation during 5-HT application failed to induce LTD. Thus, the co-activation of 5- $\mathrm{HT}_{2}$ receptors and NMDA receptors is critical for the induction of LTD in OFC L2/3 PyNs. The dis-
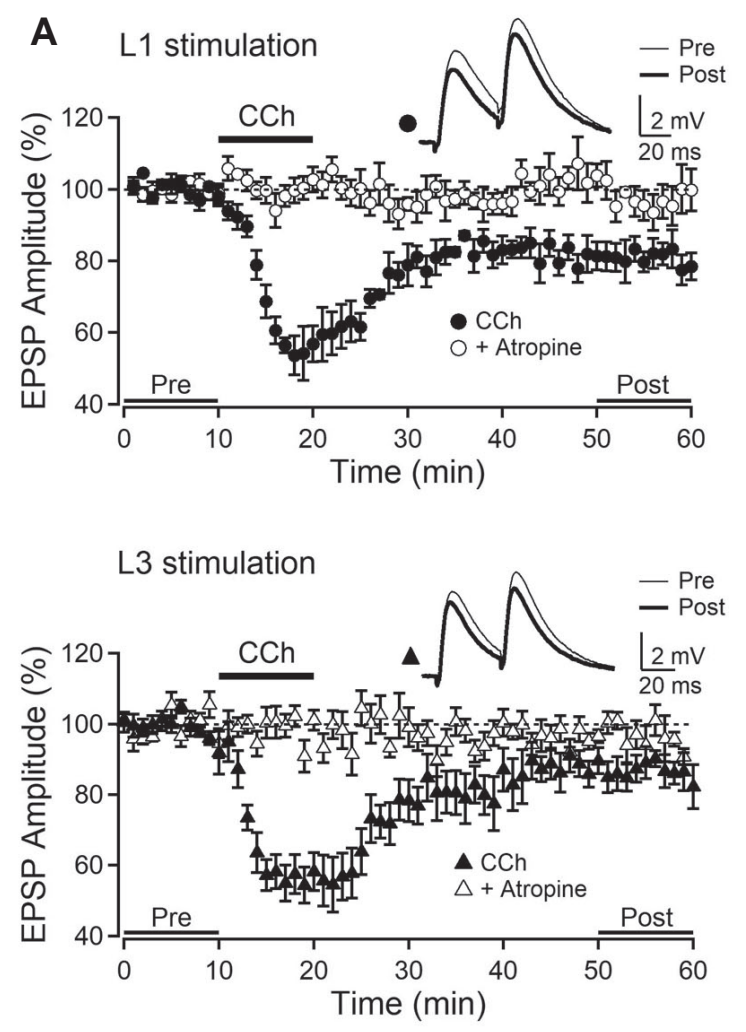
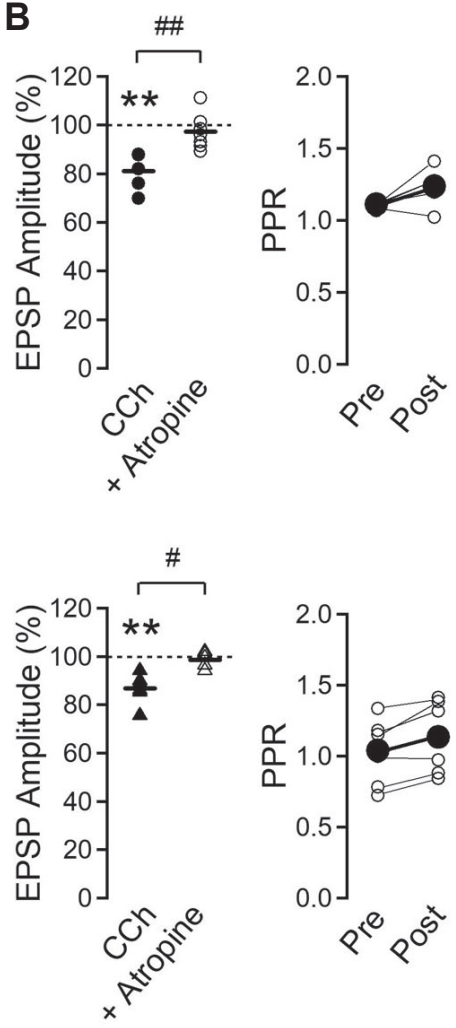

Fig. 6. Cholinergic induction of longterm depression (LTD). (A)Time course of average EPSP amplitude evoked by $\mathrm{L} 1$ and L3 stimulation. Carbachol (CCh, 10 $\mu \mathrm{M}$ ) was applied in bath solution (closed circle: $n=9$, closed triangle: $n=6$ ). Atropine $(10 \mu \mathrm{M})$ was applied to the bath solution throughout the experiment (open circle: $\mathrm{n}=7$, open triangle: $\mathrm{n}=5$ ). Insets show average EPSPs taken at the time indicated from a representative experiment. (B) Left panels show individual data and averages (thick solid lines). Right panels show the change in pairedpulse ratio (PPR) of closed symbols of the left panels. EPSP, excitatory postsynaptic potential. ${ }^{* *} p<0.01$ compared with the baseline, ${ }^{\#} \mathrm{p}<0.05,{ }^{\# \#} \mathrm{p}<0.01$. 
crepancy between previous studies in the MPFC and the present study might be attributed to the different cortical areas and layers [47].

In the current study, chelating intracellular $\mathrm{Ca}^{2+}$ with BAPTA blocked L3-LTD. Influx of extracellular $\mathrm{Ca}^{2+}$ from NMDA receptors under $5-\mathrm{HT}_{2}$ receptor activation could be the source of increased intracellular $\mathrm{Ca}^{2+}$. Otherwise, $\mathrm{PLC}$ activation by $5-\mathrm{HT}_{2}$ receptor-coupled Gq protein could increase intracellular $\mathrm{Ca}^{2+}$ via release from $\mathrm{IP}_{3}$-sensitive stores. In the primary visual cortex, $5-\mathrm{HT}_{2}$ receptor activation triggered $\mathrm{Ca}^{2+}$ release in the soma and the $\mathrm{IP}_{3}$-mediated facilitation of inhibitory currents was restricted to the perisomatic area, but not L1 [9]. Thus, this previous findings suggest that $\mathrm{Ca}^{2+}$ release from $\mathrm{IP}_{3}$-sensitive stores via activation of $5-\mathrm{HT}_{2}$ receptors might lead to the induction of L3-LTD in the OFC.

\section{Cholinergic LTD in the prefrontal cortex}

Cholinergic regulation of synaptic plasticity in the brain is associated with essential brain functions such as information processing, learning, memory, and attention [31,48,49]. LTD at glutamatergic synapses of L5 PyNs was mediated by mAChRs in the adult mPFC [26,27]. In the present study, in contrast to layerspecific 5-HT induction of LTD, muscarinic stimulation induced LTD in both inputs activated by L1 and L3 stimulation in L2/3 PyNs of the OFC. The magnitude of LTD ( 19\%) was similar to that of L3-LTD induced by 5-HT application. In our previous study, the magnitude of muscarinic-induced LTD in perisomatic inputs of the primary visual cortex was $\sim 25 \%$ [8]. Thus, these findings suggest that the low magnitude of LTD might be an intrinsic property of L2/3 PyNs in the OFC. Although muscarinic and serotonergic stimulation induced LTD, they showed different layer specificity. Thus, these results suggest that different neuromodulators play a role in the induction of long-term synaptic plasticity depending on their own layer-specific patterns. Differential expression of receptors, ion channels and intracellular signaling molecules between dendritic compartments could contribute to the variable effect of neuromodulators.

\section{Implications of layer-specific neuromodulation of synaptic transmission}

Cortical PyNs extend their dendrites to the other layers and integrate the inputs from other brain structures in different layers. The L2/3 and L5 PyNs carry multiple perisomatic dendrites including basal dendrites around the soma and a single apical dendrite extending up to $\mathrm{L} 1$ as dendritic tufts [2,33]. These dendrites integrate synaptic inputs as compartments with characteristic membrane distribution of ion channels and intracellular $\mathrm{Ca}^{2+}$ release [7,33]. In L2/3 PyNs of the primary sensory cortex, topdown associative inputs from other cortical areas and bottom-up sensory inputs from the thalamus terminate mainly in distal api- cal dendrites and basal dendrites, respectively [32]. Likewise, in the PFC, feedback connections from other cortical areas as well as the nonspecific thalamus target dendrites in L1 while inputs from amygdala and hippocampus and feedforward cortical inputs terminate in perisomatic dendrites $[18,20,21]$. In the $\mathrm{mPFC}$, L1 even receives thalamocortical projection and corticocortical inputs in a sublaminar fashion [19]. Thus, the layer-specific nature of synaptic transmission and plasticity of cortical PyNs is important in understanding the cortical integration of information. It is suggested that neuromodulators control synaptic transmission in a pathway-specific manner depending on brain states such as attention, sleep and mood [50]. We previously demonstrated layerspecific muscarinic and serotonergic modulation of synaptic transmission in the primary visual cortex [7-9]. In the present study, 5-HT induced LTD in perisomatic inputs but not in distal apical inputs located in L1 of the OFC while muscarinic stimulation induced LTD in both inputs. This layer-specific neuromodulation may represent an important mechanism of neuromodulatory control of information processing depending on the brain state.

\section{ACKNOWLEDGEMENTS}

This work was supported by a grant (2016R1A2B2016533) from the Basic Science Research Program through the National Research Foundation of Korea funded by the Ministry of Education, Science and Technology.

\section{CONFLICTS OF INTEREST}

The authors declare no conflicts of interest.

\section{REFERENCES}

1. Larkum ME, Petro LS, Sachdev RNS, Muckli L. A perspective on cortical layering and layer-spanning neuronal elements. Front Neuroanat. 2018;12:56.

2. Larkman AU. Dendritic morphology of pyramidal neurones of the visual cortex of the rat: III. Spine distributions. J Comp Neurol. 1991;306:332-343.

3. Sjöström PJ, Rancz EA, Roth A, Häusser M. Dendritic excitability and synaptic plasticity. Physiol Rev. 2008;88:769-840.

4. Marder E, O'Leary T, Shruti S. Neuromodulation of circuits with variable parameters: single neurons and small circuits reveal principles of state-dependent and robust neuromodulation. Annu Rev Neurosci. 2014;37:329-346.

5. Celada P, Puig MV, Artigas F. Serotonin modulation of cortical neurons and networks. Front Integr Neurosci. 2013;7:25.

6. Hasselmo ME, Sarter M. Modes and models of forebrain cholinergic neuromodulation of cognition. Neuropsychopharmacology. 2011;36:52-73. 
7. Cho KH, Jang HJ, Jo YH, Singer W, Rhie DJ. Cholinergic induction of input-specific late-phase LTP via localized $\mathrm{Ca}^{2+}$ release in the visual cortex. J Neurosci. 2012;32:4520-4530.

8. Joo K, Cho KH, Youn SH, Jang HJ, Rhie DJ. Layer-specific involvement of endocannabinoid signaling in muscarinic-induced longterm depression in layer $2 / 3$ pyramidal neurons of rat visual cortex. Brain Res. 2019;1712:124-131.

9. Jang HJ, Cho KH, Park SW, Kim MJ, Yoon SH, Rhie DJ. Layer-specific serotonergic facilitation of IPSC in layer 2/3 pyramidal neurons of the visual cortex. J Neurophysiol. 2012;107:407-416.

10. Puig MV, Gulledge AT. Serotonin and prefrontal cortex function: neurons, networks, and circuits. Mol Neurobiol. 2011;44:449-464.

11. Miller EK, Cohen JD. An integrative theory of prefrontal cortex function. Annu Rev Neurosci. 2001;24:167-202.

12. Ongür D, Price JL. The organization of networks within the orbital and medial prefrontal cortex of rats, monkeys and humans. Cereb Cortex. 2000;10:206-219.

13. Dalley JW, Cardinal RN, Robbins TW. Prefrontal executive and cognitive functions in rodents: neural and neurochemical substrates. Neurosci Biobehav Rev. 2004;28:771-784.

14. Izquierdo A. Functional heterogeneity within rat orbitofrontal cortex in reward learning and decision making. J Neurosci. 2017;37:10529-10540.

15. Wallis JD. Cross-species studies of orbitofrontal cortex and valuebased decision-making. Nat Neurosci. 2011;15:13-19.

16. Sul JH, Kim H, Huh N, Lee D, Jung MW. Distinct roles of rodent orbitofrontal and medial prefrontal cortex in decision making. Neuron. 2010;66:449-460.

17. Gerfen CR, Clavier RM. Neural inputs to the prefrontal agranular insular cortex in the rat: horseradish peroxidase study. Brain Res Bull. 1979;4:347-353.

18. Gabbott PL, Warner TA, Jays PR, Bacon SJ. Areal and synaptic interconnectivity of prelimbic (area 32), infralimbic (area 25) and insular cortices in the rat. Brain Res. 2003;993:59-71.

19. Cruikshank SJ, Ahmed OJ, Stevens TR, Patrick SL, Gonzalez AN, Elmaleh M, Connors BW. Thalamic control of layer 1 circuits in prefrontal cortex. J Neurosci. 2012;32:17813-17823.

20. Aggleton JP, Wright NF, Rosene DL, Saunders RC. Complementary patterns of direct amygdala and hippocampal projections to the macaque prefrontal cortex. Cereb Cortex. 2015;25:4351-4373.

21. Kuramoto E, Iwai H, Yamanaka A, Ohno S, Seki H, Tanaka YR, Furuta T, Hioki H, Goto T. Dorsal and ventral parts of thalamic nucleus submedius project to different areas of rat orbitofrontal cortex: a single neuron-tracing study using virus vectors. J Comp Neurol. 2017;525:3821-3839.

22. Woolf NJ, Butcher LL. Cholinergic systems mediate action from movement to higher consciousness. Behav Brain Res. 2011;221:488498.

23. Smiley JF, Goldman-Rakic PS. Serotonergic axons in monkey prefrontal cerebral cortex synapse predominantly on interneurons as demonstrated by serial section electron microscopy. J Comp Neurol. 1996;367:431-443.

24. Kirkwood A. Serotonergic control of developmental plasticity. Proc Natl Acad Sci U S A. 2000;97:1951-1952.

25. Zhong P, Liu W, Gu Z, Yan Z. Serotonin facilitates long-term depression induction in prefrontal cortex via p38 MAPK/Rab5mediated enhancement of AMPA receptor internalization.J Physiol.
2008;586:4465-4479.

26. Martin HG, Bernabeu A, Lassalle O, Bouille C, Beurrier C, PelissierAlicot AL, Manzoni OJ. Endocannabinoids mediate muscarinic acetylcholine receptor-dependent long-term depression in the adult medial prefrontal cortex. Front Cell Neurosci. 2015;9:457.

27. Huang CC, Hsu KS. Activation of muscarinic acetylcholine receptors induces a nitric oxide-dependent long-term depression in rat medial prefrontal cortex. Cereb Cortex. 2010;20:982-996.

28. Ohashi S, Matsumoto M, Togashi H, Ueno K, Yoshioka M. The serotonergic modulation of synaptic plasticity in the rat hippocampomedial prefrontal cortex pathway. Neurosci Lett. 2003;342:179-182.

29. Paxinos G, Watson C. The rat brain in stereotaxic coordinates. 6th ed. Amsterdam: Academic Press/Elsevier; 2007.

30. Kay AR, Alfonso A, Alford S, Cline HT, Holgado AM, Sakmann B, Snitsarev VA, Stricker TP, Takahashi M, Wu LG. Imaging synaptic activity in intact brain and slices with FM1-43 in C. elegans, lamprey, and rat. Neuron. 1999;24:809-817.

31. Kirkwood A, Rozas C, Kirkwood J, Perez F, Bear MF. Modulation of long-term synaptic depression in visual cortex by acetylcholine and norepinephrine. J Neurosci. 1999;19:1599-1609.

32. Shipp S. Structure and function of the cerebral cortex. Curr Biol. 2007;17:R443-R449.

33. Spruston N. Pyramidal neurons: dendritic structure and synaptic integration. Nat Rev Neurosci. 2008;9:206-221.

34. Berthoux C, Barre A, Bockaert J, Marin P, Bécamel C. Sustained activation of postsynaptic $5-\mathrm{HT}_{2 \mathrm{~A}}$ receptors gates plasticity at prefrontal cortex synapses. Cereb Cortex. 2019;29:1659-1669.

35. Kim HS, Jang HJ, Cho KH, Hahn SJ, Kim MJ, Yoon SH, Jo YH, Kim MS, Rhie DJ. Serotonin inhibits the induction of NMDA receptordependent long-term potentiation in the rat primary visual cortex. Brain Res. 2006;1103:49-55.

36. Jang HJ, Cho KH, Park SW, Kim MJ, Yoon SH, Rhie DJ. Effects of serotonin on the induction of long-term depression in the rat visual cortex. Korean J Physiol Pharmacol. 2010;14:337-343.

37. Park SW, Jang HJ, Cho KH, Kim MJ, Yoon SH, Rhie DJ. Developmental switch of the serotonergic role in the induction of synaptic long-term potentiation in the rat visual cortex. Korean J Physiol Pharmacol. 2012;16:65-70.

38. Kojic L, Dyck RH, Gu Q, Douglas RM, Matsubara J, Cynader MS. Columnar distribution of serotonin-dependent plasticity within kitten striate cortex. Proc Natl Acad Sci U S A. 2000;97:1841-1844.

39. Kojic L, Gu Q, Douglas RM, Cynader MS. Serotonin facilitates synaptic plasticity in kitten visual cortex: an in vitro study. Brain Res Dev Brain Res. 1997;101:299-304.

40. Cornea-Hébert V, Riad M, Wu C, Singh SK, Descarries L. Cellular and subcellular distribution of the serotonin $5-\mathrm{HT}_{2 \mathrm{~A}}$ receptor in the central nervous system of adult rat. J Comp Neurol. 1999;409:187209.

41. Clemett DA, Punhani T, Duxon MS, Blackburn TP, Fone KC. Immunohistochemical localisation of the $5-\mathrm{HT}_{2 \mathrm{C}}$ receptor protein in the rat CNS. Neuropharmacology. 2000;39:123-132.

42. Li QH, Nakadate K, Tanaka-Nakadate S, Nakatsuka D, Cui Y, Watanabe $\mathrm{Y}$. Unique expression patterns of $5-\mathrm{HT}_{2 \mathrm{~A}}$ and $5-\mathrm{HT}_{2 \mathrm{C}}$ receptors in the rat brain during postnatal development: Western blot and immunohistochemical analyses. J Comp Neurol. 2004;469:128-140.

43. Barre A, Berthoux C, De Bundel D, Valjent E, Bockaert J, Marin P, Bécamel C. Presynaptic serotonin 2A receptors modulate thalamo- 
cortical plasticity and associative learning. Proc Natl Acad Sci U S A. 2016;113:E1382-E1391.

44. Otmakhova NA, Otmakhov N, Lisman JE. Pathway-specific properties of AMPA and NMDA-mediated transmission in CA1 hippocampal pyramidal cells. J Neurosci. 2002;22:1199-1207.

45. Acker CD, Hoyos E, Loew LM. EPSPs measured in proximal dendritic spines of cortical pyramidal neurons. eNeuro. 2016;3:ENEURO.0050-15.2016.

46. Williams SR, Stuart GJ. Dependence of EPSP efficacy on synapse location in neocortical pyramidal neurons. Science. 2002;295:19071910.
47. Rao Y, Daw NW. Layer variations of long-term depression in rat visual cortex. J Neurophysiol. 2004;92:2652-2658.

48. Markram H, Segal M. Long-lasting facilitation of excitatory postsynaptic potentials in the rat hippocampus by acetylcholine. $J$ Physiol. 1990;427:381-393.

49. Picciotto MR, Higley MJ, Mineur YS. Acetylcholine as a neuromodulator: cholinergic signaling shapes nervous system function and behavior. Neuron. 2012;76:116-129.

50. Hasselmo ME, McGaughy J. High acetylcholine levels set circuit dynamics for attention and encoding and low acetylcholine levels set dynamics for consolidation. Prog Brain Res. 2004;145:207-231. 